\title{
Novel Greener Microwave-Assisted Deprotection Methodology for the 1,3-Dioxolane Ketal of Isatin Using Calix $[n]$ arenes
}

\author{
Lucas B. Barbosa, ${ }^{a}$ Tiago L. da Silva, ${ }^{b}$ Michelle J. C. Rezende, ${ }^{a}$ Bianca N. M. da Silva, ${ }^{a}$ \\ Rodrigo N. Guzzoc ${ }^{c}$ and Bárbara V. Silva ${ }^{\circledR *, a}$ \\ anstituto de Química, Universidade Federal do Rio de Janeiro, CT, Bloco A, Cidade Universitária, \\ 21945-970 Rio de Janeiro-RJ, Brazil \\ ${ }^{b}$ Curso de Química, Universidade Federal do Rio de Janeiro, Cidade Universitária, \\ Av. Aluizio da Silva Gomes, 50, Novo Cavaleiros, 27930-560 Macaé-RJ, Brazil \\ 'Instituto de Ensino Superior da Região Serrana, 29645-000 Santa Maria de Jetibá-ES, Brazil
}

\begin{abstract}
In this work, the combined use of $p$-sulfonic acid-calix[ $n]$ arene and microwave energy to hydrolyze the 1,3-dioxolane ketal of isatin was evaluated with excellent results. This is the first time that $p$-sulfonic acid-calix $[n]$ arene has been used as the catalyst in a ketal hydrolysis reaction and the deprotection of the ketone carbonyl of isatin is reported. The presence of $2.5 \mathrm{~mol} \%$ of $p$-sulfonic acid-calix [4,6]arene at $160{ }^{\circ} \mathrm{C}$ resulted in over $96 \%$ conversion of this ketal in $10 \mathrm{~min}$, with the additional advantage of using water as a solvent. This catalytic system (aqueous phase containing $p$-sulfonic acid-calix[4]arene) was reused for five consecutive cycles, with a conversion above $96 \%$ maintained. This reusable system is not practicable using $p$-toluenesulfonic acid and $p$-hydroxybenzenesulfonic acid as catalysts since both are extracted to the organic phase with the reaction product. The hydrolysis of 1,3-dioxolane ketal of isatins with different substituents $\left(\mathrm{CH}_{3}\right.$, $\mathrm{I}, \mathrm{Br}, \mathrm{Cl}, \mathrm{F}, \mathrm{NO}_{2}$ ) in the aromatic ring was also evaluated. The protecting group of 5-methyl-isatin was removed with $73 \%$ conversion using $2.5 \mathrm{~mol} \%$ of $p$-sulfonic acid-calix[4]arene at $160{ }^{\circ} \mathrm{C}$ for $5 \mathrm{~min}$. In contrast, the ketal of 5-nitro-isatin reached $80 \%$ conversion using the same conditions after $40 \mathrm{~min}$.
\end{abstract}

Keywords: 1,3-dioxolane ketal of isatin, $p$-sulfonic acid-calix $[n]$ arene, reusable catalytic system, supramolecular catalysis

\section{Introduction}

Circular processes have been identified as the next step to achieve chemical processes of maximal functionality. ${ }^{1}$ The current concept is to design processes that maximize the functionality while minimizing the amounts of catalyst, by-products or residues, and also include features such as recycling, self-separation, solvent-free methods, and atomic economy. ${ }^{2,3}$ The 12 principles of green chemistry philosophy have been comprehensively deployed as governmental policy and academic practice in order to develop new environmentally safe methodologies in accordance with the circular economy. ${ }^{4,5}$

The use of environmentally friendly solvents, microwave as a heating source, and recycling of catalysts or reaction

*e-mail: barbara@iq.ufrj.br

Editors handled this article: Teodoro S. Kaufman and Brenno A. D. Neto (Associate) media are examples of green procedures in organic synthesis. All of these characteristics are incorporated in our method using $p$-sulfonated calix $[n]$ arenes as a catalyst. Calix $[n]$ arenes are cup-shaped macrocycles which can be synthesized as tetramers, hexamers, or octamers. ${ }^{6}$ This class of compounds has wide applications including liquid crystal, ${ }^{7}$ sensors, ${ }^{8,9}$ stationary phase of chromatography ${ }^{10}$ as well as a catalyst. ${ }^{11}$ Calix $[n]$ arenes have been proven to be a versatile host in host-guest catalysis to promote different chemical reactions and to work as useful greener recyclable micro-reactors in water, and in solvent-free conditions. ${ }^{11,12}$

Some recent applications of $p$-sulfonic acid-calix $[n]$ arenes as catalyst include the esterification of fatty acid, ${ }^{13}$ the three-component Povarov reaction between aromatic anilines and two equivalents of 2,3-dihydrofuran,,${ }^{14}$ and the fructose dehydration reaction to produce 5-hydroxymethylfurfural. ${ }^{15}$ Figure 1 shows the chemical structures of $p$-sulfonic acid-calix $[n]$ arenes (SCX4 and SCX6). 

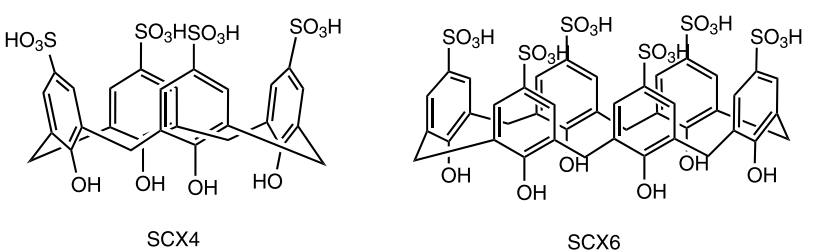

Figure 1. Chemical structures of $p$-sulfonic acid-calix[4]arene (SCX4) and $p$-sulfonic acid-calix[6]arene (SCX6).

Calix $[n]$ arenes can perform supramolecular catalysis by creating a microenvironment suitable for catalystsubstrate interaction, due to compatible geometry and intermolecular interactions between the two molecules. ${ }^{16}$ Calix $[n]$ arenes fit these conditions and have their catalytic ability intricately linked to their organized structure with the substrate. ${ }^{17-19}$ Among these molecules, SCX4 was studied in "olefin metathesis", and it was observed that it acts as a microreactor promoting an organized microenvironment to speed up the reaction. ${ }^{17}$

Guzmán-Percástegui et al. ${ }^{18}$ found that a functionalized calix[8]arene was an efficient catalyst because it achieved high conversion in the $\mathrm{C}-\mathrm{S}$ coupling; the efficiency was attributed to the supramolecular structure, studied by modelling, which was responsible for capturing the substrate from the solvent. The "oxyethylated calix[4] arene" presented by Mirgorodskaya et al. ${ }^{19}$ was directly linked to the catalysis of esters in a similar way to enzymatic catalysis. Thus, calix $[n]$ arenes are included as nanoreactors ${ }^{20}$ and artificial enzymes ${ }^{16}$ because, in addition to promoting catalysis, their structure can recognize the substrate and separate it from the medium.

In this work, we focus on the catalytic activity of $p$-sulfonated calix $[n]$ arenes on the 1,3-dioxolane ketal of isatin. Isatin (1) (Figure 2) has a multifunctional chemical structure that makes it highly versatile in organic synthesis and allows it to be used as a scaffold for the synthesis of complex molecules. ${ }^{21}$ Isatin derivatives have been extensively studied in medicinal chemistry due to their therapeutic activities..$^{22}$ Many analogues of isatin have been prepared to find new bioactive compounds, particularly those with antiviral, anti-inflammatory, anticonvulsant, antichagasic, and antitumor activity. ${ }^{21,23-26}$ This is the case for the antitumor compound sunitinib (2), ${ }^{27}$ the analgesic pemedolac $(\mathbf{3}),{ }^{28}$ isatins bearing halogens and nitro groups in the aromatic ring $(\mathbf{4}, \mathbf{5}$, and $\mathbf{6}),{ }^{29,30}$ and isatin-type 5'-(4-alkyl/aryl-1H-1,2,3-triazoles) (7 and 8). ${ }^{31,32}$ In nature, isatin derivatives can be found in the parotid gland of Bufo, bacteria (Streptomyces albus), fungi (Chaetomium globosum), and other organisms such as mammals and plants. ${ }^{33-35}$

For the synthesis of these important molecules, protecting groups are needed. A protecting group must react selectively and with a good yield to provide a stable, protected compound in the reaction medium. Selective, rapid and good yield removal is another important

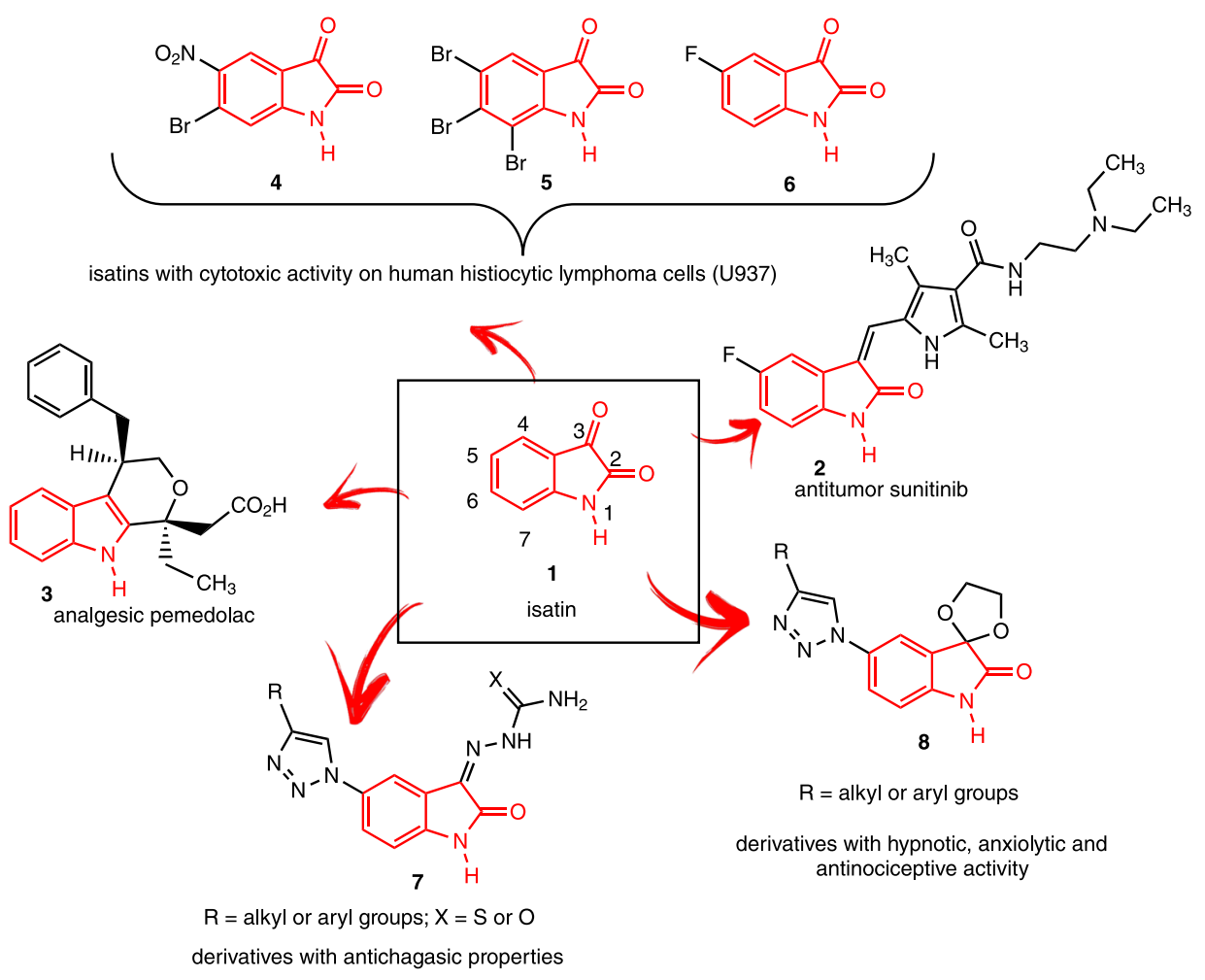

Figure 2. Chemical structures of isatin (1) and derivatives (2-8) with biological activities. 
characteristic of a good protecting group. ${ }^{36}$ Dioxolane ketal is a protecting group for carbonyl functionalities and can easily be deprotected in acidic medium. ${ }^{36}$ Other methods of deprotection of ketals, such as the use of wet silica gel, ${ }^{37}$ ultrasound,$^{38}$ and clay ${ }^{39}$ are described in the literature.

Deprotection of dioxolane ketal from isatin usually requires an acid medium, long treatment times under a high-temperature reflux system using a conventional heating source, and ultimate has a low yield. Some results obtained by our research group showed that it is not an easy task. Dioxolane ketals of isatin were very resistant to hydrolysis using glacial acetic acid combined with concentrated hydrochloric acid $3 \mathrm{~mol} \mathrm{~L}-1\left(\mathrm{v} \mathrm{v}^{-1}, 4 \mathrm{~mL} / 2 \mathrm{~mL}\right)$ under conventional heating. This setup resulted in partial deprotection after a long reflux time. Furthermore, a severe deprotection condition was investigated using trifluoroacetic acid refluxed for $48 \mathrm{~h}$, which produced the same results. ${ }^{40}$

Calix $[n]$ arenes have not previously been used as a catalyst in the hydrolysis of ketals. The present work investigated the hydrolysis of isatin ketal (spiro [ $[1,3]$ dioxolane-2,3'-indolin]-2'-one) using $p$-sulfonic acidcalix $[n]$ arene $(n=4,6)$ as the catalyst, microwave radiation as the heating source and water as the solvent. The goal was to develop an efficient and fully recyclable catalytic system for hydrolysis reactions in agreement with green chemistry principles and the circular economy.

\section{Experimental}

\section{General}

All reagents and solvents were purchased from SigmaAldrich (São Paulo, Brazil) and Tedia (Rio de Janeiro, Brazil), respectively, and were used without further purification.

The nuclear magnetic resonance spectra of hydrogen $\left({ }^{1} \mathrm{H}\right.$ NMR) and carbon $\left({ }^{13} \mathrm{C}\right.$ NMR) were collected on a Bruker equipment (Bruker Daltonics, Bremen, Germany), operating at 200, 400 or $500 \mathrm{MHz}$ for ${ }^{1} \mathrm{H}$ nuclei and 50, 100 or $125 \mathrm{MHz}$ for ${ }^{13} \mathrm{C}$. The solvent used was deuterated dimethyl sulfoxide (DMSO- $d_{6}$ ) or deuterated chloroform $\left(\mathrm{CDCl}_{3}\right)$. Chemical shifts $(\delta)$ were expressed in parts per million (ppm) values and coupling constants $(J)$ in hertz $(\mathrm{Hz})$.

The exact masses of calix $[n]$ arene compounds were obtained using a Fourier-transform ion cyclotron resonance mass spectrometer (FT-ICR-MS) (model 9.4 T Solarix, Bruker Daltonics, Bremen, Germany) in negative electrospray ionization (ESI) mode. Samples were solubilized in methanol.

\section{Synthesis of calix[n]arenes}

The used calix $[n]$ arene catalysts, SCX4 and SCX6, were synthesized in three consecutive reactions, according to the procedures reported in the literature. Firstly, $p$-tert-butylcalix $[4,6]$ arenes were synthesized from $p$-tert-butylphenol and formaldehyde. ${ }^{41,42}$ The $p$-tert-butyl groups were removed using aluminum chloride to obtain the calix $[4,6]$ arenes, ${ }^{43}$ which were then submitted to the sulfonation reaction. ${ }^{44}$ The products obtained in each reaction and the final products (SCX4 and SCX6) were characterized by ${ }^{1} \mathrm{H}$ NMR, ${ }^{13} \mathrm{C}$ NMR, infrared (IR), using $\mathrm{KBr}$, and ESI(-)-FT-ICR MS. Characterization data and spectra of the catalysts can be found in the Supplementary Information (SI) section.

\section{Synthesis of ketal isatins}

The 1,3-dioxolane ketal of isatin and its derivatives with substituent on the aromatic ring, used as starting material on the hydrolysis catalytic tests, were synthesized as previously published by our group. The substituted isatins were obtained from two different routes. The compounds 5-iodo-isatin (9), 5-bromo-isatin (10), 5-chloro-isatin (11), and 5-nitro-isatin (12) were synthesized directly from isatin. ${ }^{45-48}$ The synthesis of 5-fluoro-isatin (6) and 5-methylisatin (13) started from 4-fluoro-aniline and 4-methylaniline, respectively. The anilines were converted to the corresponding isonitrosoacetanilides, which then generated the substituted isatins. ${ }^{49}$ For the ketals preparation, isatin (or its substituted derivatives), ethylene glycol, toluene and $p$-toluenesulfonic acid were used. ${ }^{50}$ All synthesized isatin derivatives were characterized by ${ }^{1} \mathrm{H} \mathrm{NMR},{ }^{13} \mathrm{C}$ NMR and IR. Characterization data and spectra of the isatins and 1,3-dioxolane ketals can also be found in the SI section.

\section{General procedure for the hydrolysis}

$0.15 \mathrm{mmol}$ of 1,3-dioxolane ketal, $10 \mathrm{~mL}$ of water and the required amount of catalyst were transferred to a $30 \mathrm{~mL}$ reaction vessel, which was sealed and heated under microwave irradiation in Anton Paar Monowave 300 (Graz, Austria) at constant temperature and $800 \mathrm{rpm}$ constant magnetic stirring. After the reaction, the mixture was cooled, and ethyl acetate $(5 \times 3.3 \mathrm{~mL})$ was added to extract the product (isatin) and unreacted starting material (ketal). After extraction, the organic layer was dried over anhydrous sodium sulfate and ethyl acetate was removed by evaporation under reduced pressure. All of the reactions were performed in duplicate and the replicates presented a difference from 1 to $3 \%$ of conversion. 


\section{Conversion analysis}

The reaction conversion was determined by gas chromatography-mass spectrometry (GC-MS) using internal standard (IS) calibration curves for the quantification of 1,3-dioxolane ketal of isatin (14) and isatin (1). Indole was used as IS. The reaction conversion of 1,3-dioxolane ketal of isatin derivatives with substituent on the aromatic ring was calculated using only calibration curve for the quantification of the corresponding 1,3-dioxolane ketal (15-20).

The 1,3-dioxolane ketal standard stock solution was prepared by weighting $12.5 \mathrm{mg}$ of ketal in a $25.0 \mathrm{~mL}$ volumetric flask and completing with ethyl acetate. The stock solution was then stored at $-20{ }^{\circ} \mathrm{C}$. Standard ketal solutions were prepared from this stock solution in the range of approximately $0.050-0.400 \mathrm{mg} \mathrm{mL}^{-1}$. The standard ketal solutions were prepared by the addition of a known volume $(1.0,2.0,4.0$, and $8.0 \mathrm{~mL})$ of the ketal standard stock solution and $1.0 \mathrm{~mL}$ of a $2.0 \mathrm{mg} \mathrm{mL}^{-1}$ indole solution in a $10.0 \mathrm{~mL}$ volumetric flask, completing with ethyl acetate. The ketal concentrations were selected in order to construct standard curves equivalent to 10, 20, 40 and $80 \% \mathrm{~m} / \mathrm{m}$ of the starting material in the isolated product. All points were obtained in triplicate and were randomly injected.

The isatin standard stock solution was prepared by weighting $25 \mathrm{mg}$ of isatin in a $25.0 \mathrm{~mL}$ volumetric flask and completing with ethyl acetate. The stock solution was then stored at $-20{ }^{\circ} \mathrm{C}$. Standard isatin solutions were prepared from this stock solution in the range of approximately 0.100-0.495 $\mathrm{mg} \mathrm{mL}^{-1}$. The standard isatin solutions were prepared by the addition of a known volume (1.0, 3.0, 4.0, 4.5 , and $4.95 \mathrm{~mL}$ ) of the isatin standard stock solution and $1.0 \mathrm{~mL}$ of a $2.0 \mathrm{mg} \mathrm{mL}^{-1}$ indole solution (IS) in a $10.0 \mathrm{~mL}$ volumetric flask, completing with ethyl acetate. The isatin concentrations were selected in order to construct standard curves equivalent to $20,60,80,90$, and $99 \% \mathrm{~m} \mathrm{~m}^{-1}$ of isatin in the isolated product. All points were obtained in triplicate and were randomly injected.

GC-MS analyses were performed on a Shimadzu GC-QP2010 (Kyoto, Japan) gas chromatography coupled to a Shimadzu GCMS-QP2010 mass spectrometer. Electron ionization at $70 \mathrm{eV}$ ionization energy was used. An RXi-1MS (100\% methylpolysiloxane) capillary column with $30 \mathrm{~m}, 0.25 \mathrm{~mm}$ internal diameter, and $0.25 \mu \mathrm{m}$ phase film diameter was used. The carrier gas was helium at a flow rate of $2.4 \mathrm{~mL} \mathrm{~min}^{-1}$. The temperature program was an isothermal period of $3 \mathrm{~min}$ at $50{ }^{\circ} \mathrm{C}$, then increased at $15{ }^{\circ} \mathrm{C} \mathrm{min}-1$ to $280{ }^{\circ} \mathrm{C}$, and final isothermal period of $5 \mathrm{~min}$. Injection volume was $1.0 \mu \mathrm{L}$ in split mode and with
1:10 split ratio. The injector temperature was $280{ }^{\circ} \mathrm{C}$. The transfer line and ion source were held at 290 and $230{ }^{\circ} \mathrm{C}$, respectively. All samples were analyzed in SCAN mode in the mass range of 60-600 $\mathrm{u}$. The injection samples were prepared by weighting $5.0 \mathrm{mg}$ of isolated product in a $10.0 \mathrm{~mL}$ volumetric flask containing $1.0 \mathrm{~mL}$ of a $2.0 \mathrm{mg} \mathrm{mL}^{-1}$ IS solution and completing with ethyl acetate.

The standard calibration parameters are summarized in Table 1. The limits of detection of isatin ketal and isatin were determined from the calibration curve parameters. The values were $0.021 \mathrm{mg} \mathrm{mL}^{-1}\left(4 \% \mathrm{~m} \mathrm{~m}^{-1}\right)$ for ketal and $0.094 \mathrm{mg} \mathrm{mL}^{-1}\left(19 \% \mathrm{~m} \mathrm{~m}^{-1}\right)$ for isatin.

Table 1. Parameters of the standard solution analytical equation of isatin and ketals

\begin{tabular}{lcc}
\hline Molecule & $\mathrm{R}^{2}$ & Equation \\
\hline Isatin & 0.9926 & $y=0.5813 x-0.2745$ \\
\hline Isatin ketal (R=) & & \\
\hline $\mathrm{H}$ & 0.9993 & $y=0.5768 x-0.0616$ \\
$\mathrm{CH}_{3}$ & 0.9938 & $y=0.7013 x-0.0387$ \\
$\mathrm{~F}$ & 0.9960 & $y=0.6250 x+0.0149$ \\
$\mathrm{Cl}$ & 0.9999 & $y=0.6854 x-0.0545$ \\
$\mathrm{Br}$ & 0.9999 & $y=0.6116 x-0.0724$ \\
$\mathrm{I}$ & 0.9995 & $y=0.3695 x-0.0690$ \\
$\mathrm{NO}_{2}$ & 0.9933 & $y=0.5077 x-0.1326$ \\
\hline
\end{tabular}

$\mathrm{R}^{2}$ : coefficient of determination.

Reuse of the catalytic system

The reuse of the catalytic system was tested in the hydrolysis of the isatin ketal (14) $(0.15 \mathrm{mmol})$ using $2.5 \mathrm{~mol} \%$ of $p$-sulfonic acid-calix[4]arene and $10 \mathrm{~mL}$ of water under microwave irradiation at $160{ }^{\circ} \mathrm{C}$ for $10 \mathrm{~min}$. After extraction with ethyl acetate, the aqueous phase containing the catalyst was used in a new cycle simply by adding the equivalent load of starting material $(0.15 \mathrm{mmol}$ of ketal). The same catalytic system was used for four cycles. Reaction conversion was determined by GC-MS for all cycles.

\section{Results and Discussion}

Evaluation of calix[4,6]arenes as catalyst in hydrolysis of 1,3-dioxolane ketal of isatin

The catalytic performances of $p$-sulfonic acid-calix[6] arene (SCX6) and $p$-sulfonic acid-calix[4]arene (SCX4) were investigated in the hydrolysis of the 1,3-dioxolane ketal of isatin (14) using microwave heating at a constant temperature. Initially, the effect of the amount of catalyst 
was investigated in order to achieve the maximum conversion in the shortest reaction time. The results are shown in Table 2.

Table 2. Hydrolysis of the 1,3-dioxolane ketal of isatin (14) using different types of catalyst

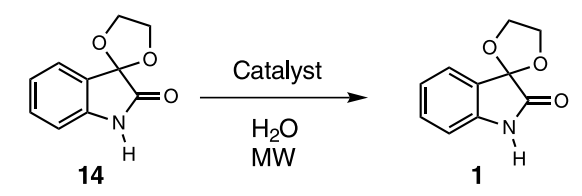

\begin{tabular}{lccccc}
\hline entry & Catalyst & $\begin{array}{c}\text { Catalyst / } \\
\text { mol\% }\end{array}$ & $\begin{array}{c}\text { Temperature / } \\
{ }^{\circ} \mathrm{C}\end{array}$ & $\begin{array}{c}\text { time / } \\
\mathrm{min}\end{array}$ & $\begin{array}{c}\text { Conversion }{ }^{\mathrm{a}} \\
\%\end{array}$ \\
\hline 1 & SCX6 & 0.3 & 150 & 40 & $>96$ \\
2 & SCX6 & 0.6 & 150 & 35 & $>96$ \\
3 & SCX6 & 0.7 & 150 & 30 & $>96$ \\
4 & SCX6 & 2.0 & 150 & 20 & $>96$ \\
5 & SCX6 & 2.5 & 160 & 10 & $>96$ \\
6 & SCX6 & 2.5 & 160 & 5 & 92 \\
7 & SCX4 & 2.5 & 160 & 5 & 91 \\
8 & SCX4 & 2.5 & 160 & 10 & $>96$ \\
9 & PTSA & 2.5 & 160 & 5 & $<19$ \\
10 & PTSA & 2.5 & 160 & 30 & 92 \\
11 & PHSA $^{2.5}$ & 2.5 & 160 & 30 & 93 \\
12 & SCX4 $^{\mathrm{b}}$ & 2.5 & 160 & 10 & 57 \\
13 & SCX4 $^{\mathrm{c}}$ & 2.5 & 160 & 10 & 38 \\
\hline
\end{tabular}

a Limit of detection of ketal is $4 \% \mathrm{~m} \mathrm{~m}^{-1}$ and isatin is $19 \% \mathrm{~m} \mathrm{~m}^{-1}$; b,cin these tests, ${ }^{\mathrm{b}} 0.64 \mathrm{mmol}$ of $\mathrm{NaCl}$ and ${ }^{\mathrm{c}} \mathrm{CaSO}_{4}$ was added to the reaction medium. SCX4: $p$-sulfonic acid-calix[4]arene; SCX6: $p$-sulfonic acid-calix[6] arene; PTSA: p-toluenesulfonic acid; PHSA: $p$-hydroxybenzenesulfonic acid.

Increasing the SCX6 concentration provided the same conversion in less time (entries 1-6, Table 2). Conversion higher than $96 \%$ was achieved after running the reaction for $10 \mathrm{~min}$ using $2.5 \mathrm{~mol} \%$ of both calix $[4,6]$ arenes at $160^{\circ} \mathrm{C}$. High conversions were observed using $p$-toluenesulfonic acid (PTSA) and $p$-hydroxybenzenesulfonic acid (PHSA) as catalysts under the same conditions only after $30 \mathrm{~min}$ of reaction (entries 10 and 11, Table 2). Hydrolysis was also carried out in a round-bottom flask connected to a reflux condenser using the traditional heat transfer apparatus (an oil bath). The reaction was performed with $0.15 \mathrm{mmol}$ of 1,3-dioxolane ketal of isatin, $2.5 \mathrm{~mol} \%$ of SCX4 and $10 \mathrm{~mL}$ of water under reflux. The maximum conversion (>96\%) was observed after $5 \mathrm{~h}$, emphasizing the advantage of using microwave energy. It is important to highlight that there was no hydrolysis of the ketal, zero conversion, when the reaction was carried out without catalyst.

In order to investigate the low hydrolysis rate observed after 5 min of reaction when PTSA was used as a catalyst, the conversion was evaluated according to the amount of sulfonic groups present. Table 3 shows two sets of results. In entries 1-4, the catalysts were used at the same concentration $(2.5 \mathrm{~mol} \%)$. In entries $5-8$, the catalyst concentration was adjusted so that all tests had the same percentage of sulfonic groups (5.0 mol\% sulfonic group). Another parameter used to evaluate the difference between the catalysts was $\mathrm{pH}$. The $\mathrm{pH}$ of the reaction medium was determined in all tests, and it ranged from 3.0 to 3.5 for the first set of experiments (entries 1-4) and from 3.1 to 3.3 for the second (entries 5-8).

Table 3. Hydrolysis of the 1,3-dioxolane ketal of isatin (14), using $10 \mathrm{~mL}$ of water as the solvent, at $160{ }^{\circ} \mathrm{C}$ for $5 \mathrm{~min}$

\begin{tabular}{lccccc}
\hline entry & Catalyst & $\begin{array}{c}\text { Catalyst / } \\
\text { mol\% }\end{array}$ & $\begin{array}{c}\mathrm{SO}_{3} \mathrm{H}^{\mathrm{a}} / \\
\mathrm{mol} \%\end{array}$ & $\mathrm{pH}$ & $\begin{array}{c}\text { Conversion } \\
\%\end{array}$ \\
\hline 1 & SCX6 & 2.5 & 15.0 & 3.2 & 92 \\
2 & SCX4 & 2.5 & 10.0 & 3.0 & 91 \\
3 & PHSA & 2.5 & 2.5 & 3.4 & 31 \\
4 & PTSA & 2.5 & 2.5 & 3.5 & $<19$ \\
5 & SCX6 & 0.83 & 5.0 & 3.3 & 34 \\
6 & SCX4 & 1.25 & 5.0 & 3.3 & 55 \\
7 & PHSA & 5.0 & 5.0 & 3.1 & 52 \\
8 & PTSA & 5.0 & 5.0 & 3.2 & 42 \\
\hline
\end{tabular}

${ }^{a}$ Concentration catalyst multiplied by the number of sulfonic groups present in the structure; 'blimit of detection of ketal is $4 \% \mathrm{~m} \mathrm{~m}^{-1}$ and isatin is $19 \% \mathrm{~m} \mathrm{~m}^{-1}$. SCX4: $p$-sulfonic acid-calix[4]arene; SCX6: $p$-sulfonic acid-calix[6]arene; PTSA: $p$-toluenesulfonic acid; PHSA: $p$-hydroxybenzenesulfonic acid.

When catalysts using the same reaction time and concentration were compared, it was evident that the best options are the calix[4,6]arenes (entries 1 and 2, Table 3). However, when the comparison took into account the percentage of sulfonic groups, SCX4 was the most efficient, and the hexamer had the lowest conversion (entries 5-8). This difference of results between the calix $[4,6]$ arenes is due to their geometry and mobility. The high mobility between eight possible conformers of the calix[6]arene allows them to be converted through the passage of the hydroxyl groups inside the cavity of the structure. ${ }^{51} \mathrm{In}$ contrast, SCX4, like the other calix[4]arenes, has less mobility between its four conformations (cone, partial cone, 1,2-alternate and 1,3-alternate) than the corresponding hexamer, ${ }^{52}$ corroborating the importance of the organization of the system for this catalysis. This variation of mobility was first seen by Gutsche and Bauer ${ }^{51}$ in temperaturedependent ${ }^{1} \mathrm{H}$ NMR studies. The other catalysts, PHSA and PTSA, showed conversion values between those obtained by SCX4 and SCX6.

As a second indication of the efficiency of SCX4, the $\mathrm{pH}$ of each catalytic system was measured. It was used 
to evaluate whether the reaction mechanism occurs by general or specific acid catalysis. In specific acid catalysis, the reaction rate depends only on the $\mathrm{pH}$; in general acid catalysis, the conjugate base of the acid also influences the speed, since it acts with reduced energy from the activated complex. ${ }^{52}$ In order to verify this aspect of the reaction, the deprotection of the isatin ketal was also performed with hydrochloric acid, maintaining the same reaction conditions. The medium had acid concentration and $\mathrm{pH}$ equal to the reaction performed with SCX4, $2.5 \mathrm{~mol} \%$ and $\mathrm{pH} 3.0$, but reached only $70 \%$ of conversion, while SCX4 had a high conversion of $91 \%$ (entry 2, Table 3). This result shows that the catalyst influences the slow step of the reaction.

It is important to consider that in general acid catalysis, the conjugate base of the catalyst is involved in the slow step, which occurs during proton transfer. In this case, the reaction rate depends on factors in addition to the $\mathrm{pH} .{ }^{53}$ Analyzing the $\mathrm{pH}$ values when the percentage of sulfonic groups among the tested catalysts is equivalent (entries 5-8, Table 3), the medium with PHSA has a lower $\mathrm{pH}$ than the medium with SCX4 or SCX6. If the hydrolysis was occurring via specific acid catalysis, this $\mathrm{pH}$ difference would cause an increase in the reaction rate when PHSA is used. However, it is observed that the extra effect provided by the SCX4 catalyst compensates for the $\mathrm{pH}$ effect leading to close conversion percentages.

Another aspect we explored is the ionic strength because it increases the efficiency of heat exchange in the reaction medium irradiated by microwave energy due to the greater vibration of the polarized molecules in the generated electromagnetic field. ${ }^{54}$ Due to this fact, we tested whether the presence of inorganic salts would improve the conversion of the reaction. However, the increase in ionic strength led to a reduction in the percentage of hydrolysis. The deprotection of the isatin ketal was performed with $2.5 \mathrm{~mol} \% \mathrm{SCX} 4$ in the presence of $0.64 \mathrm{mmol} \mathrm{NaCl}$ or $\mathrm{CaSO}_{4}$, maintaining the same reaction conditions. The conversions were 57 and $38 \%$ in the presence of $\mathrm{NaCl}$ and $\mathrm{CaSO}_{4}$, respectively, much lower than without these compounds, as shown in Table 2 , entry 8 . This result is attributed to the complexation of $\mathrm{Na}^{+}$and $\mathrm{Ca}^{2+}$ cations by SCX4, as shown by Coleman et al. ${ }^{55}$ and Suwinska et al. ${ }^{56}$ Thus, the action of SCX4 acidic sites in the transition state is again evident since there is a negative effect on the hydrolysis when the cation occupies them.

\section{Reuse of the catalytic system}

After identifying the catalytic efficiency of SCX4, we focused on the reuse of the catalytic system, using water as a solvent, and separating the reaction product from the medium by extraction with ethyl acetate. The advantage of using the calix $[n]$ arene as a catalyst is that it remains in the aqueous phase, and this catalyst system can then be immediately used for a new batch by simply adding the starting material (ketal). The reaction product is obtained from the evaporation of the organic solvent, which is recovered by condensation and reused in the next extraction. Thus, this system complies with the principles of green chemistry. The use of PTSA and PHSA as a catalyst in this system is not feasible because both migrate to the organic phase with the product formed.

The reuse of the aqueous phase (catalytic system) was carried out for four consecutive reactions using SCX4 as a catalyst for $10 \mathrm{~min}$ at $160{ }^{\circ} \mathrm{C}$. The conversion was over $96 \%$ in all batches. Furthermore, the yields obtained after liquid-liquid extraction in ethyl acetate were greater than $90 \%$ for each catalyst recycle.

Hydrolysis of 1,3-dioxolane ketal of isatins with different substituents

The catalytic system was used in the hydrolysis of 1,3-dioxolane ketal of isatins with different substituents (15-20). The purpose was to evaluate the electronic effects on the hydrolysis reaction catalyzed by SCX4 (Figure 3).
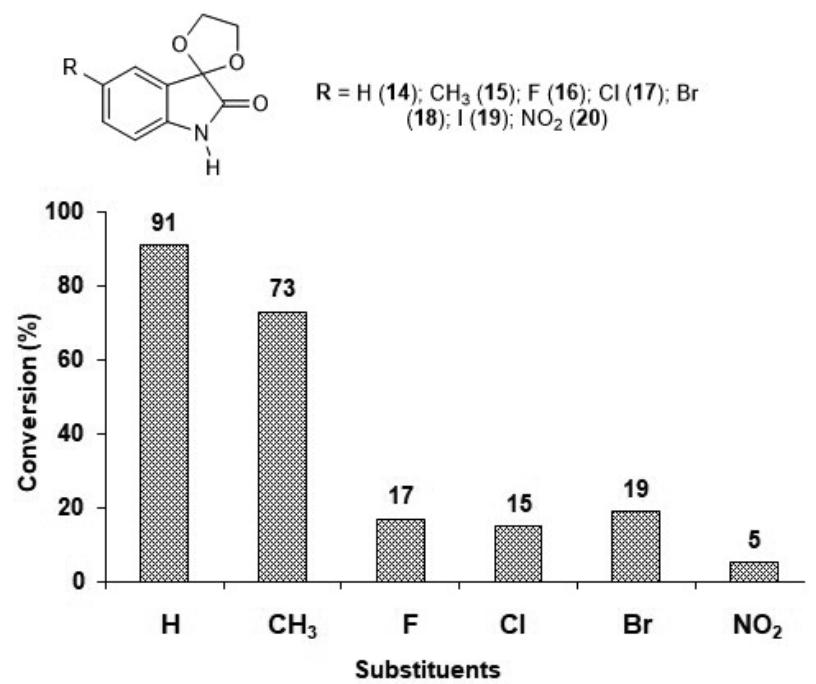

Figure 3. Hydrolysis of ketals of isatin with different substituents, using $2.5 \mathrm{~mol} \%$ of SCX 4 at $160{ }^{\circ} \mathrm{C}$ for $5 \mathrm{~min}$.

The presence of the substituents in the aromatic ring can change the reactivity of isatin due to electron donation or withdrawal and also possibly due to steric hindrance. The methyl group usually donates electrons by $\sigma$ conjugation; however, the conversion was lower when compared to a 
ketal without a substituent. In order to explain the lower conversion of $\mathbf{1 5}$ to the respective isatin, we determined that steric effects were important for the poor solubility of the starting material in the aqueous medium due to the presence of the methyl group or difficulty in accessing the catalyst (SCX4).

The conversion decreased significantly in the presence of halogenated substituents. Unfortunately, the method did not apply to the ketal of 5-iodo-isatin (19). The starting material did not solubilize in the reaction medium, even after 5 min at $160^{\circ} \mathrm{C}$.

The conversion from the compound containing the nitro group was even smaller when compared to the other deactivating substituents. The nitro group withdraws electrons by conjugation with the $\pi$-bond system of the aromatic ring. Although the 5-nitro-isatin ketal (20) was the most resistant to hydrolysis, the efficiency of our methodology was proven. We reached at least $80 \%$ conversion by extending the reaction time to $40 \mathrm{~min}$ at $160{ }^{\circ} \mathrm{C}$ with $2.5 \mathrm{~mol} \%$ of SCX 4 .

\section{Conclusions}

The removal of the ketal protective group of isatin and its derivatives has been a challenge. There are no studies in the literature directed specifically at the hydrolysis of isatin ketals and the classic methods tested by the group were not efficient. Based on the results of this work, the use of SCX4, microwave energy, and water as a solvent emerges as a fast, efficient and reusable catalytic system for the hydrolysis of the isatin ketal dioxolane. The variation of the concentration of sulfonic acid groups, the evaluation of the $\mathrm{pH}$ and the presence of inorganic salts indicates that the reaction occurs via general acid catalysis. The catalytic system was reused for four cycles, maintaining the maximum conversion. The product was removed from the reaction medium by extraction with an organic solvent, also recoverable and reusable; only the starting material for a new batch was added to the aqueous medium containing the catalyst. The developed system complies with several of the principles of green chemistry, such as the non-generation of waste, the reuse of the catalyst and the use of safe and recoverable solvents. The advantage of using SCX4 or SCX6 as catalysts is that they remain in the aqueous phase, and do not require recovery for reuse. In contrast, classical sulfonic catalysts such as PTSA and PHSA are soluble in the organic phase, which requires additional steps for recovery. In addition, our methodology was successful in reaching $80 \%$ conversion in the hydrolysis of the most resistant ketal studied. Therefore, the application of SCX4 to this system is of great interest in drug design and catalysis in general.

\section{Supplementary Information}

Supplementary information containing the characterization data and spectra of the catalysts, isatins, and 1,3-dioxolane ketals of isatins is available free of charge at http://jbcs.sbq.org.br as PDF file.

\section{Acknowledgments}

This work was supported by the Brazilian National Agency of Petroleum, Natural Gas and Biofuels (ANP) and the Rio de Janeiro Research Foundation (FAPERJ, 200.593/2017).

\section{Author Contributions}

Lucas B. Barbosa was responsible for investigation and writing original draft; Tiago L. da Silva for conceptualization, methodology, writingreview and editing; Michelle J. C. Rezende for conceptualization, methodology, writing-review and editing; Bianca N. M. da Silva for investigation and writing original draft; Rodrigo N. Guzzo for investigation and writing original draft; Bárbara V. Silva for conceptualization, methodology, writing-review and editing.

\section{References}

1. Zimmerman, J. B.; Anastas, P. T.; Erythropel, H. C.; Leitner, W.; Science 2020, 367, 397.

2. Matlin, S. A.; Mehta, G.; Hopf, H.; Krief, A.; Nat. Chem. 2016, 8, 393.

3. Liu, J.; Mooney, H.; Hull, V.; Davis, S. J.; Gaskell, J.; Hertel, T.; Lubchenco, J.; Seto, K. C.; Gleick, P.; Kremen, C.; Li, S.; Science 2015, 347, 963.

4. Warner, J. C.; Anastas, P. T.; Green Chemistry: Theory and Practice, revised ed.; Oxford University Press: New York, 2000.

5. Chen, T.-L.; Kim, H.; Pand, S.-Y.; Tseng, P.-C.; Lina, Y.-P.; Sci. Total Environ. 2020, 716, 136998.

6. Sardjono, R. E.; Rachmawati, R. In Green Chemical Processing and Synthesis, $1^{\text {st }}$ ed.; Srour, H.; Karamé, I., eds.; Intech Open Science/Open Minds: Hong Kong, 2017, p. 2513.

7. Sharma, V. S.; Shah, A. P.; Sharma, A. S.; New J. Chem. 2019 , 43, 3556 .

8. Tanwar, S.; Ho, J. A.; Magi, E.; Talanta 2013, 117, 352.

9. McMahon, G.; O’Malley, S.; Nolan, K.; Diamond, D.; Arkivoc 2003, 2003, 23.

10. Ding, C.; Qu, K.; Li, Y.; Hu, K.; Liu, H.; Ye, B.; Wu, Y.; Zhang, S.; J. Chromatogr. A 2007, 1170, 73.

11. Tashakkorian, H.; Lakouraj, M. M.; Rouhi, M.; Int. J. Med. Chem. 2015, 2015, ID 738202.

12. de Rosa, M.; La Manna, P.; Sorientea, A.; Gaeta, C.; Talotta, C.; Neri, P.; RSC Adv. 2016, 6, 91846; Castro, G. A. D.; Fernandes, 
S. A.; Sustainable Energy Fuels 2021, 5, 108; Zacchi, C. H. C.; Vieira, S. S.; Ardisson, J. D.; Araujo, M. H.; de Fátima, A.; J. Saudi Chem. Soc. 2019, 23, 1060; Sayin, S.; Yilmaz, M.; Tetrahedron 2016, 72, 6528; Shimizu, S.; Shimada, N.; Sasaki, Y.; Green Chem. 2006, 8, 608.

13. Fernandes, S. A.; Natalino, R.; Varejão, E. V. V.; Catal. Sci. Technol. 2014, 4, 1369.

14. Rezende, T. R. M.; Varejão, J. O. S.; Sousa, A. L. L. A.; Castañeda, S. M. B.; Fernandes, S. A.; Org. Biomol. Chem. 2019, 17, 2913.

15. Pereira, S. P. S.; Varejão, J. O. S.; Fátima, A.; Fernandes, S. A.; Ind. Crops Prod. 2019, 138, 111492.

16. Wang, T.; Fan, X.; Hou, C.; Liu, J.; Curr. Opin. Struct. Biol. 2018, 51, 19.

17. Tomasek, J.; Seßler, M.; Gröger, H.; Schatz, J.; Molecules 2015 , 20, 19130.

18. Guzmán-Percástegui, E.; Hernándeza, D. J.; Castillo, I.; Chem. Commun. 2016, 52, 3111.

19. Mirgorodskaya, A. B.; Yackevich, E. I.; Kudryashova, Y. R.; Kashapov, R. R.; Solovieva, S. E.; Gubaidullin, A. T.; Antipin, I. S.; Zakharova, L. Y.; Konovalov, A. I.; Colloids Surf., B 2014, 117, 497.

20. Deraedt, C.; Astruc, D.; Coord. Chem. Rev. 2016, 324, 106.

21. da Silva, J. F. M.; Garden, S. J.; Pinto, A. C.; J. Braz. Chem. Soc. 2001, 12, 273.

22. Sonam, V.; Kakkar, R.; MedChemComm 2019, 10, 351.

23. Lashgari, N.; Ziarani, G. M.; Arkivoc 2012, 2012, 277.

24. Santos, I. S.; Guerra, F. S.; Bernardino, L. F.; Fernandes, P. D.; Hamerski, L.; Silva, B. V.; J. Braz. Chem. Soc. 2019, 30, 198.

25. Silva, B. V.; J. Braz. Chem. Soc. 2013, 24, 707.

26. Giorno, T. B. S.; Silva, B. V.; Pinto, A. C.; Fernandes, P. D.; Life Sci. 2016, 152, 189.

27. Sun, S.; Schiller, J. H.; Crit. Rev. Oncol. Hematol. 2007, 62, 93.

28. Mobilio, D.; Humber, L. G.; Katz, A. H.; Demerson, C. A.; Hughes, P.; Brigance, R.; Conway, K.; Shah, U.; Williams, G.; J. Med. Chem. 1988, 31, 2211.

29. Vine, K. L.; Locke, J. M.; Ranson, M.; Pyne, S. G.; Bremner, J. B.; Bioorg. Med. Chem. 2007, 15, 931.

30. Vine, K. L.; Matesic, L.; Locke, J. M.; Ranson, M.; Skropeta, D.; Anti-Cancer Agents Med. Chem. 2009, 9, 397.

31. Montes, G. C.; Silva, B. N.; Rezende, B.; Sudo, R. T.; Ferreira, V. F.; Silva, F. C.; Pinto, A. C.; Silva, B. V.; Zapata-Sudo, G.; Molecules 2017, 22, 800.

32. Silva, B. N.; Sales Jr., P. A.; Romanha, A. J.; Murta, S. M. F.; Lima, C. H. S.; Albuquerque, M. G.; D’Elia, E.; Rodrigues, J. G. A.; Ferreira, V. F.; Silva, F. C.; Pinto, A. C.; Silva, B. V.; Med. Chem. 2019, 15, 240.
33. Medvedev, A.; Buneeva, O.; Glover, V.; Biologics 2007, 1, 151.

34. Grafe, U.; Radics, L.; J. Antibiot. 1985, 39, 162.

35. Awad, N. E.; Kassem, H. A.; Hamed, M. A.; El-Naggar, M. A. A.; El-Feky, A. M. M.; J. Mycol. Med. 2014, 24, e35.

36. Grenne, T. W.; Wuts, P. G. M.; The Role of Protective Groups in Organic Synthesis, $3^{\text {rd }}$ ed.; John Wiley \& Sons: New York, 1999.

37. Huet, F.; Lechevallier, A.; Pellet, M.; Conia, J. M.; Synthesis 1978, 1, 63.

38. Lee, A. S.-Y.; Cheng, C.-L.; Tetrahedron 1997, 53, 14255.

39. Gautier, E. C. L.; Graham, A. E.; McKillop, A.; Standen, S. P.; Taylor, R. J. K.; Tetrahedron Lett. 1997, 38, 1881.

40. Silva, B. N.: Síntese e Avaliação da Atividade anti-Trypanosoma Cruzi de Derivados da Isatina; $\mathrm{PhD}$ Thesis, Federal University of Rio de Janeiro, Rio de Janeiro, Brazil, 2017, available at http://objdig.ufrj.br/13/teses/864125.pdf, accessed in November 2021.

41. Gutsche, C. D.; Dhawan, B.; No, K. H.; Muthukrishnan, R.; J. Am. Chem. Soc. 1981, 103, 3782.

42. Gupta, A.; Khopkar, S. M.; Talanta 1995, 42, 1493.

43. Gutsche, C. D.; Lin, L.-G.; Tetrahedron 1986, 42, 1633.

44. Shinkai, S.; Araki, K.; Tsubaki, T.; Arimura, T.; Manabe, O.; J. Chem. Soc., Perkin Trans. 1 1987, 2297.

45. Garden, S. J.; Torres, J. C.; Melo, S. C. S.; Lima, A. S.; Pinto, A. C.; Lima, E. L. S.; Tetrahedron Lett. 2001, 42, 2089.

46. Garden, S. J.; Torres, J. C.; Ferreira, A. A.; Silva, R. B.; Pinto, A. C.; Tetrahedron Lett. 1997, 38, 1501.

47. Ribeiro, N. M.; Silva, B. V.; Violante, F. A.; Rezende, C. M.; Pinto, A. C.; Org. Prep. Proced. Int. 2005, 37, 265.

48. Silva, B. V.; Esteves, P. M.; Pinto, A. C.; J. Braz. Chem. Soc. 2011, 22, 257.

49. Marvel, C. S.; Hiers, G. S.; Org. Synth. Coll. 1941, 1, 327.

50. Ribeiro, N. M.; Pinto, A. C.; Silva, B. V.; Violante, F. A.; Dias, M. O.; Catal. Commun. 2007, 8, 2130.

51. Gutsche, C. D.; Bauer, L. J.; J. Am. Chem. Soc. 1985, 107, 6052.

52. Gutsche, C. D.; Dhawan, B.; Levine, J. A.; No, K. H.; Bauer, L. J.; Tetrahedron 1983, 39, 409.

53. Anslyn, E. V.; Dougherty, D. A.; Modern Physical Organic Chemistry, $1^{\text {st }}$ ed.; University Science Books: Sausalito, 2005.

54. Sanseverino, A. M.; Quim. Nova 2002, 25, 660.

55. Coleman, A.; Bott, S.; Morley, S. D.; Means, C.; Robinson, K.; Zhang, H.; Atwood, J.; Angew. Chem., Int. Ed. 1998, 27, 1361.

56. Suwinska, K.; Janneau, E.; Tauran, Y.; Coleman, A. W.; J. Inclusion Phenom. Macrocyclic Chem. 2014, 79, 177.

Submitted: September 30, 2021 Published online: December 7, 2021 